\title{
Psychometric analysis of the brief symptom inventory 18 (BSI-18) in a representative German sample
}

\author{
Gabriele Helga Franke ${ }^{1 *}$, Susanne Jaeger ${ }^{1}$, Heide Glaesmer ${ }^{2}$, Claus Barkmann ${ }^{3}$, Katja Petrowski ${ }^{4}$ and Elmar Braehler ${ }^{2,5}$
}

\begin{abstract}
Background: The BSI-18 contains the three six-item scales somatization, depression, and anxiety as well as the Global Severity Index (GSI), including all 18 items. The BSI-18 is the latest and shortest of the multidimensional versions of the Symptom-Checklist 90-R, but its psychometric properties have not been sufficiently clarified yet.

Methods: Based on a representative sample of $N=2516$ participants (aged 14-94 years), detailed psychometric analyses were carried out.

Results: The internal consistency was good: Somatization $a=.82$, Depression $a=.87$, Anxiety $a=.84$ and GSI $a=.93$. Confirmatory factor analysis supported the three scales as second-order and GSI as first-order factors. The model fit based on RMSEA is good but that model fit based on CFI and TLI are too low.

Conclusions: Therefore, it is a very short, reliable instrument for the assessment of psychological distress. The BSI-18 can be used to reliably assess psychological distress in the general population. However, further studies need to evaluate the usefulness of standardization in clinical samples.
\end{abstract}

Keywords: Psychological distress, BSI-18, Reliability, Factorial structure

\section{Background}

Internationally, the SCL-90 $[16,21,22]$ is the most used questionnaire for the assessment of psychological distress, especially in clinical practice [45]. However, it is a very long and time-consuming questionnaire, which is why two Brief Symptom Inventory versions of the Symptom Checklist SCL-90-R were developed [12, 18, 20, 21]: the Brief Symptom Inventory with 53 items (BSI; [13, 17, 19, 23]), which measures psychological distress, and its shortened version, the Brief Symptom Inventory with 18 items (BSI-18; [11, 14, 24]).

The Brief Symptom Inventory with 53 items was developed by Derogatis using a factor analysis and maintaining the scale structure with the reduced item number of the SCL-90-R (somatization, obsessive-compulsive, interpersonal sensitivity, depression, anxiety, anger-hostility, phobic anxiety paranoid ideation and psychoticism). In Germany,

\footnotetext{
* Correspondence: Gabriele.franke@hs-magdeburg.de

'Department of Rehabilitation Psychology, University of Applied Sciences

Magdeburg-Stendal, Osterburger Str. 25, 39576 Hansestadt Stendal, Germany

Full list of author information is available at the end of the article
}

the BSI is mainly used for quality management in psychotherapy (e.g. [28]).

In order to reduce and prevent an overload to the patients and to ensure an easy screening-tool, the BSI-18 was developed with highest clinical relevance. The BSI18 contains only the three six-item scales somatization (SOMA), anxiety (ANX), depression (DEPR), and the global Scale Global Severity Index (GSI). (They are documented in Table 1). Contrary to the SCL-90-R and the BSI-53, the BSI-18 scores were calculated by sum scores. The GSI therefore ranges between $0-72$ and the three scales between $0-24$. The application studies demonstrated that the BSI-18 is a suitable instrument for measuring psychological distress and comorbidities in patients with different mental and somatic illnesses (e.g. $[1,4,8,9,10,29,38,39,46,48])$. This instrument is also used in longitudinal studies [5, 6, 37].

Until now, there have only been three studies which address the applicability and psychometric properties of the German version of the BSI-18 in patients after renal 
Table 1 Item- and scale statistics, reliability, and convergent validity in the total sample $(N=2516)$

\begin{tabular}{|c|c|c|c|c|c|c|}
\hline No & Item & $M(S D)$ & $\begin{array}{l}\text { Corrected item-total } \\
\text { correlation }\end{array}$ & $\begin{array}{l}\text { a Without the } \\
\text { item }\end{array}$ & $\begin{array}{l}\text { PHQ-Depression } \\
\text { correlations }\end{array}$ & $\begin{array}{l}\text { PHQ-Anxiety } \\
\text { correlations }\end{array}$ \\
\hline \multicolumn{2}{|r|}{ Scale 1: Somatization $(a=.82)$} & $\begin{array}{l}\sum 1.46 \\
(2.58)\end{array}$ & & & \multirow[t]{7}{*}{$.52^{* *}$} & \multirow[t]{7}{*}{$.48^{* *}$} \\
\hline 1 & Faintness or dizziness & $\begin{array}{l}0.19 \\
(0.51)\end{array}$ & .56 & .80 & & \\
\hline 4 & Pains in heart or chest & $\begin{array}{l}0.23 \\
(0.56)\end{array}$ & .61 & .79 & & \\
\hline 7 & Nausea or upset stomach & $\begin{array}{l}0.28 \\
(0.63)\end{array}$ & .49 & .81 & & \\
\hline 10 & Trouble getting your breath & $\begin{array}{l}0.22 \\
(0.57)\end{array}$ & .65 & .78 & & \\
\hline 13 & $\begin{array}{l}\text { Numbness or tingling in parts of } \\
\text { your body }\end{array}$ & $\begin{array}{l}0.22 \\
(0.60)\end{array}$ & .55 & .80 & & \\
\hline 16 & Feeling weak in parts of your body & $\begin{array}{l}0.33 \\
(0.69)\end{array}$ & .66 & .77 & & \\
\hline \multicolumn{2}{|c|}{ Scale 2: Depression $(a=.87)$} & $\begin{array}{l}\sum 1.76 \\
(3.23)\end{array}$ & & & \multirow[t]{7}{*}{$.72^{* *}$} & \multirow[t]{7}{*}{$.71^{* *}$} \\
\hline 2 & Feeling no interest in things & $\begin{array}{l}0.36 \\
(0.69)\end{array}$ & .67 & .85 & & \\
\hline 5 & Feeling lonely & $\begin{array}{l}0.42 \\
(0.82)\end{array}$ & .66 & .85 & & \\
\hline 8 & Feeling blue & $\begin{array}{l}0.27 \\
(0.67)\end{array}$ & .78 & .83 & & \\
\hline 11 & Feelings of worthlessness & $\begin{array}{l}0.26 \\
(0.69)\end{array}$ & .74 & .83 & & \\
\hline 14 & Feeling hopeless about the future & $\begin{array}{l}0.39 \\
(0.83)\end{array}$ & .73 & .84 & & \\
\hline 17 & Thoughts of ending your life & $\begin{array}{l}0.07 \\
(0.36)\end{array}$ & .51 & .88 & & \\
\hline \multicolumn{2}{|c|}{ Scale 3: Anxiety $(a=.84)$} & $\begin{array}{l}\sum 1.44 \\
(2.59)\end{array}$ & & & \multirow[t]{7}{*}{$.63^{* *}$} & \multirow[t]{7}{*}{$.72^{* *}$} \\
\hline 3 & Nervousness or shakiness inside & $\begin{array}{l}0.27 \\
(0.62)\end{array}$ & .66 & .80 & & \\
\hline 6 & Feeling tense or keyed up & $\begin{array}{l}0.50 \\
(0.77)\end{array}$ & .59 & .83 & & \\
\hline 9 & Suddenly scared for no reason & $\begin{array}{l}0.17 \\
(0.50)\end{array}$ & .62 & .81 & & \\
\hline 12 & Spells of terror or panic & $\begin{array}{l}0.10 \\
(0.39)\end{array}$ & .66 & .82 & & \\
\hline 15 & $\begin{array}{l}\text { Feeling so restless you couldn't sit } \\
\text { still }\end{array}$ & $\begin{array}{l}0.23 \\
(0.60)\end{array}$ & .66 & .80 & & \\
\hline 18 & Feeling fearful & $\begin{array}{l}0.19 \\
(0.53)\end{array}$ & 63 & .81 & & \\
\hline \multicolumn{2}{|c|}{ Global Severity Index $(a=.93)$} & $\begin{array}{l}\sum 4.66 \\
(7.44)\end{array}$ & & & $.71^{* *}$ & $.73^{* *}$ \\
\hline
\end{tabular}

** $=p<.0001$

transplantation [26] and in hospitalized psychosomatic patients $[25,49]$.

In contrast, the psychometric properties of the BSI18 were discussed internationally in 13 publications. The reliability (Cronbachs $\alpha$ ) ranged for SOMA between $\alpha_{\text {min }}=.61$ [36] and $\alpha_{\max }=.84$ [50], for DEPR between $\alpha_{\min }=.64$ [36] and $\alpha_{\max }=.92$ [43], for ANX between $\alpha_{\min }=.71$ [2] and $\alpha_{\max }=.88$ [50] and for the GSI between $\alpha_{\min }=.84$ [36] and $\alpha_{\max }=.94$ [43]. The reliability was mostly above .80 and can thus be evaluated as good. The reliability for the American norm sample $\quad(N=1134 ; \quad \alpha$-SOMA $=.74, \quad \alpha$-DEPR $=.84, \quad \alpha$ ANGS $=.79, \alpha-$ GSI $=.89 ;[14])$ is to be rated as satisfactory. 
The retest-reliability for $n=103$ psychological distressed patients after 15 days without intervention was satisfactory with values between $r_{t t}=.68$ and $r_{t t}=.82$ [2]. For validity evidence based on internal structure, a strong first factor was discussed (e.g. [3]) alike to the SCL-90-R and the BSI-53 [42]. Based on an exploratory factor analysis, the original 3-scale structure could be replicated in $n=638$ hospitalized psychosomatic patients [25]. In addition, the original scale structure was often tested by confirmatory factor analysis [25, 26, 50]. Convergent validity was shown in several studies [2, 49]. Sensitivity and specificity were first analyzed by Zabora et al. [51] using the BSI-53.

As yet, psychometric properties based on a representative sample are still not available for Germany. Therefore, the aim of this study was to (1) describe the psychological distress within the German population, to present (2) the reliability, and (3) the factorial validity.

\section{Methods}

\section{Data acquisition}

A representative sample of the general population in Germany was collected in November/ December 2009 by a demography-consulting company (USUMA, Berlin). A total of 258 sample points were used (210 in the western part and 48 in the eastern part of Germany). The households and members of these households were selected via random-route procedure. The sample was representative for the German population regarding age, gender, and education as proved by comparisons with the Federal Statistical Office. To begin with, 4091 addresses were selected; $22 \%$ had to be dropped as neutral (e.g. persons unknown), and 38\% could not be asked (e.g., due to illness, holidays, refusal, nonavailability). In the end, a total of 2520 persons could be included in the sample.

\section{Materials \\ Sample description}

The representative sample contains 2516 individuals (53.7\% female) with an average of 50.5 years of age $(\mathrm{SD}=18.6$, Range $=14-94$ years $)$. A total of seven nearly equidistant age groups were set up: ages 14-24 (10.7\%), 25-34 (11.6\%), 35-44 (16.3\%), 45-54 (17.3\%), 55-64 (16.5\%), 65-74 (17.5\%), and 75-94 (10\%). In the sample, $52 \%$ were married, $23.4 \%$ single, $11.3 \%$ divorced, and $13.2 \%$ separated. Employment: $37.9 \%$ had a full-time job, and $9.2 \%$ had a part-time job. The remainder of the sample was unemployed $(8.1 \%)$, retired (33.9\%), housewife/ house-husband (5.3\%), and 9.7\% had not yet completed their education. Educational background: $44.1 \%$ had a lower education, $36.3 \%$ an upper education, and $6.8 \%$ an advanced education;
$6.6 \%$ were university students, $4.1 \%$ were still attending school, and $2 \%$ had not graduated.

\section{Psychological assessments}

Demographic information, the BSI-18, and further psychological assessments were collected in the survey. To investigate validity evidence based on external criteria, the 4-item version of the Patient Health Questionnaire was used to screen for depression and anxiety (PHQ-4; [32-34]). All the questions apply to the two preceding weeks and are to be rated by using " $0=$ not at all", " $1=$ several days", " $2=$ more than half the days" and " $3=$ nearly every day". For statistical calculations, the answer category "0" was to be opposed to the other three categories.

\section{Statistics}

The analyses were carried out using PASW and AMOS. First, a Missing Data Analysis led to the exclusion of four participants because they showed more than the tolerated amount of missing data (tolerated $<1$ items of each scale, $<3$ items in total). At last, a total of $0.09 \%$ of the answers were missing and not assigned randomly (Little MCAR-Test: Chi-Quadrat $=550.971, d f=333, p$ $<.0001)$. Therefore they were replaced by using Multiple Imputation (MCMC in LISREL 8.15; [35]).

Descriptive statistics, reliability as well as discriminant and convergent correlations were estimated. Construct validity was tested by using the confirmatory factor analysis (CFA).

Using AMOS [31], the respective fit of the two-factor and the three-factor model was tested using CFAs. Due to the lack of multivariate normality in the data tested with the Marida-test in AMOS, the Asymptotically Distribution Free-estimator (ADF) was used for model testing [7]. According to Schermelleh-Engel, Moosbrugger, and Müller [47], a good (acceptable) model fit is a given with $\mathrm{SB} \chi^{2} / \mathrm{df}$ index below 2.0 (below 3.0), Comparative Fit Index (CFI) as well as Tucker-Lewis-Index (TLI) above .95 (above .90), Standardized Root Mean Square Residual (SRMR) below .05 (below .10), and Root Mean Square Error of Approximation (RMSEA) below .05 (below .08).

\section{Results}

Psychological distress, reliability, and convergent validity of the scales

The mean values of the 18 items and sum scores of the three scales and the GSI had a left-skewed distribution (see Table 1), Table 2 reported gender- and age differences. Internal consistency was $\alpha=.82$ for SOM, $\alpha=.87$ for DEPR, $\alpha$ $=.84$ for ANX and $\alpha=.93$ for the GSI. The corrected discriminatory power was only below .50 for item no. 7 (nausea or upset stomach). Furthermore, the elimination of item no. 17 (thoughts of ending your life) would increase the 
reliability of the scale DEPR. The Depression scale of the PHQ correlated the highest with DEPR $(r=.72)$, followed by substantial correlations with GSI $(r=.71)$, ANX $(r=.63)$, and the lowest with SOM $(r=.52)$. The Anxiety scale of the PHQ correlated quite equal with GSI $(r=.73)$, ANX $(r=.72)$, and $\operatorname{DEPR}(r=.71)$, but the lowest with SOM $(r=.48)$.

\section{Factorial validity}

The confirmatory factor analysis was used to prove the theoretical and empirical structure of the BSI-18. Due to the lack of multivariate normality in the data tested with the Marida-test in AMOS, the Asymptotically Distribution Free-estimator (ADF) was used for model testing. The three factor model (SOMA, DEPR and ANX) resulted in $\chi^{2}=$ 355, $d f=132, p<0.001 ;$ RMSEA $=.030$ [.02 - .03]; TLI = .48; $C F I=.55$ (see Table 1$)$.

Two different models were tested by using the ADFmethod and the software AMOS; model modifications were not tolerated: the theoretical one-factor-model $\left(\chi^{2}=\right.$ 526,696, $\mathrm{df}=136, p<0.001$; RMSEA $=.034$ [.031 - .037]; $\mathrm{TLI}=.12$; CFI $=.22$, Standardized $\mathrm{RMR}=.332)$ and the three-factor-model with SOMA, DEPR and ANX $\left(\chi^{2}=\right.$ 355,143, $\mathrm{df}=132, p<0.001$; RMSEA $=.026$ [.023 - .029]; $\mathrm{TLI}=.483 ; \mathrm{CFI}=.554$, Standardized $\mathrm{RMR}=.138)$. The theoretical three-scale structure with the GSI as main factor was the model tested last $\left(\chi^{2}=355,143, \mathrm{df}=132, p<\right.$ 0.001; RMSEA $=.026[.023-.029]$; TLI $=.483$; CFI $=.554$, Standardized RMR $=.138$ ).

\section{Discussion}

Up to now, the BSI-18 has not been used widely in Germany. The psychometric properties and benefits of the instrument were investigated in three samples [25,
26, 49]. For the present representative sample, the questions concerning reliability and model fit could be answered.

The reliability (Cronbach's $\alpha$ ) of the BSI-18 ( $\alpha$-SOMA $=.82, \alpha-\mathrm{DEPR}=.87, \alpha-\mathrm{ANX}=.84, \alpha-\mathrm{GSI}=.93)$ was good to very good and ranged higher than in the US standardization. The reliability of the American norm sample $\quad(N=1134 ; \quad \alpha-\mathrm{SOMA}=.74, \quad \alpha$-DEPR $=.84, \quad \alpha-$ ANGS $=.79, \alpha-$ GSI $=.89$; [14] $)$ had to be rated as satisfactory. Therefore, it can be concluded that the internal consistency of the scales can be affected by a sufficient sample procedure [41]. The internal consistency of the scale Depression could be increased by eliminating item 17 (thoughts of ending your life). This result is similar to that of other samples, but due to the clinical relevance the item should be retained.

Using the two-item scales Depression and Anxiety of the PHQ-4 [30], to analyze convergent validity, the results were quite similar to the results by Spitzer et al. [49] using a longer PHQ-version. On the one hand, corresponding BSI-18- and PHQ-subscales demonstrated highest correlations; on the other hand, the Anxiety scale of PHQ-4 correlated similarly with BSI-18-Anxiety and BSI-18-Depression. Non-corresponding scales like the BSI-18-SOMA showed lower correlations. The results by Spitzer et al. [49] and our own results were found in nonclinical samples. Regarding clinical data [25, 26], it could be concluded that the BSI-18 is more suitable to psychologically distressed than non-distressed populations.

Congruent with international $[27,40,42,50]$ and German clinical studies $[25,26]$ the three scales of the BSI18 showed the best model fits by reproducing the scale structure using the confirmatory factor analysis.

Table 2 Gender- and Age differences in the BSI-18 scales and the GSI

\begin{tabular}{|c|c|c|c|c|}
\hline Variable & SOMA & DEPR & ANX & GSI \\
\hline \multirow[t]{2}{*}{ Gender } & $F=1.7 p<0.20$ & $F=7.2 p<0.007$ & $F=8.5 p<0.004$ & $F=6.9 p<0.009$ \\
\hline & & $\eta^{2}=0.003$ & $\eta^{2}=0.003$ & $\eta^{2}=0.003$ \\
\hline Men $(n=1163)$ & $1.36(2.4)$ & $1.56(3.1)$ & $1.26(2.4)$ & $4.19(6.9)$ \\
\hline Women $(n=1353)$ & $1.54(2.7)$ & $1.92(3.3)$ & $1.59(2.7)$ & $5.07(7.8)$ \\
\hline \multirow[t]{2}{*}{ Age } & $F=36.0 p<0.0001$ & $F=5.2 p<0.0001$ & $F=2.1 p<0.05$ & $F=11.0 p<0.0001$ \\
\hline & $\eta^{2}=0.079$ & $\eta^{2}=0.012$ & $\eta^{2}=0.005$ & $\eta^{2}=0.026$ \\
\hline I: $14-24$ years $(n=270)$ & $0.85(2.2)$ I < V VI VII & $1.57(3.7) \mathrm{I}<\mathrm{VII}$ & $1.40(3.0)$ & $3.83(8.3) I<$ VII \\
\hline II: $25-34$ years $(n=293)$ & $0.70(1.8) \|<$ V VI VII & $1.27(2.5) \|<\mathrm{VII}$ & $1.09(2.1)$ & 3.05 (5.7) II < VI VII \\
\hline III: $35-44$ years $(n=410)$ & 0.79 (1.7) III < V VI VII & $1.36(2.7) \mathrm{III}<\mathrm{VII}$ & $1.35(2.3)$ & $3.50(5.8) \mathrm{III}<\mathrm{VII}$ \\
\hline IV: $45-54$ years $(n=436)$ & $1.27(2.4) \mathrm{IV}<\mathrm{VIVII}$ & $2.0(3.5)$ & $1.59(2.6)$ & 4.85 (7.6) IV < VII \\
\hline V: $55-64$ years $(n=415)$ & 1.59 (2.6) V > I II III V< VII & $1.89(3.2)$ & $1.54(2.8)$ & $5.02(7.6) \mathrm{V}<\mathrm{VII}$ \\
\hline Vl: $65-74$ years $(n=440)$ & 2.07 (2.8) VI > I II III IV VI < VII & $1.77(3.1)$ & $1.35(2.4)$ & $5.19(7.4) \mathrm{VI}>\| \mathrm{VI}<\mathrm{VII}$ \\
\hline VII: 75-94 years $(n=252)$ & 3.17 (3.5) VII > I II III IV V VI & 2.57 (3.8) VII > I II III & $1.76(3.0)$ & 7.50 (9.0) VII > I II III IV V VI \\
\hline Gender x Age & $F=1.2 p<0.30$ & $F=0.7 p<0.68$ & $F=0.9 p<0.50$ & $F=0.8 p<0.56$ \\
\hline
\end{tabular}

Comments. Mean values and standard deviations for scale sums and the GSI are presented for gender, age and their interaction. Effect sizes ( $\eta^{2}$ ) or post hoc tests are presented if the result is significant 
Nevertheless, the boundaries for a good model fit according to Schermelleh-Engel, Moosbrugger, and Müller [47] could not be reached. The model fit based on RMSEA is good but that model fit based on CFI and TLI are too low.

The remarkable strength of the present sample is its good age distribution due to representative sampling: young $(n=270$, aged $14-24)$, elderly $(n=440$, aged $65-$ $74)$, and old age $(n=252$, aged $75-94)$. Besides the strength of a large sample size as a limitation, it is not possible to draw general conclusions based on the data from a representative sample since a large sample size could easily lead to significant effects. Since the sample was representative for the normal population, the results are not offhandedly applicable to highly distressed samples [15]. In turn, the BSI-18 should be applied to different clinical samples to further replicate or reprobate the factorial structure.

In future research it would be productive to test the stability of the distress construct (test-retest reliability) and to explore connections to other distress questionnaires (convergent validity) or external ratings (criterion validity) [44]. A design with repeated measurements would allow for the comparison of factor structures across time and the determination of possible cohort effects.

The available version of the used software to measure the factor analysis with categorical indicators was applied. This should be seen as a limitation of this study and advice for future research.

\section{Conclusion}

The BSI-18 is a very short, reliable instrument for the assessment of psychological distress. The factorial structure of the instrument is very good when using confirmatory factor analyses as well as the psychometric criteria. Therefore, it is an instrument that can be used to reliably assess psychological distress in clinical samples as well as in the general population. In addition, it can be used in psychotherapy research as well as in quality assurance for psychotherapeutic long-term effects. Taking into account the good internal consistency reliability estimates and the encouraging convergent validity estimates, this preliminary validation is a good step forward in validation studies which are iterative in nature.

\footnotetext{
Abbreviations

ADF: Asymptotically distribution free-estimator; ANX: Anxiety; BSI-18: Brief Symptom Inventory (Short Version); BSI-53: Brief Symptom Inventory; CFA: Confirmatory factor analysis; CFI: Comparative fit index; DEPR: Depression; GSI: Global Severity Index; LISREL: Linear structural relations, statistical software package; MCMC: Markov chain Monte Carlo; PASW: Predictive analytics software; PHQ-4: Patient Health Questionnaire-4; RMSEA: Root mean square error of approximation; SCL-90-R: Symptom Checklist-90-revised; SOMA: Somatization; SRMR: Standardized root mean square residual; TLI: Tucker-Lewis-index; USUMA: USUMA Sozial- und Marktforschungsinstitut
}

\section{Acknowledgements}

We would like to thank Liz Orrison for the native speaker proof reading.

\section{Funding}

The study was conducted without any kind of funding.

\section{Availability of data and materials}

The data were collected upon the author's request. Further information about the data upon request by the corresponding author.

\section{Authors' contributions \\ SJ did the calculations under the supervision of GHF. GHF and KP wrote the manuscript. EB did the conception and design, financed and implemented the study. HG and CB gave advice how to construct and implement the study as well as for the calculations. All authors revised the publication critically for important intellectual content and gave final approval of the version to be published.}

\section{Competing interests}

The authors declare that they have no competing interests.

\section{Consent for publication}

All authors agree with this publication. The consents will send by the corresponding author if accepted for publication.

\section{Ethics approval and consent to participate}

All participants volunteered and received a data protection declaration in agreement with the Helsinki Declaration. The study was approved according to the ethical guidelines of the "German Professional Institutions for Social Research" (Arbeitskreis Deutscher Markt- und Sozialforschungsinstitute, Arbeitsgemeinschaft Sozialwissenschaftlicher Institute, Berufsverband Deutscher Markt- und Sozialforscher) and has the approval number: 072-1107032011. Verbal informed consent was obtained from all participants. If minors or children were enrolled verbal informed consent was obtained from the next of kin, caretaker, or guardian. Since the aspects of anonymity and voluntariness were given, there was no need for a written consent in accordance with paragraph 2 §4a of the Federal Data Protection Act, as otherwise it could have led to sample bias in this scientific investigation - due to its representative research design. The comprehensive written information of the study participants about the exact use of the collected data through a privacy sheet and an accompanying written study information is sufficient for the legislator in this case of research.

In this study, all selected participants were first informed orally about the research background of the study and its voluntary nature and the right of subsequent cancellation of own participation. Since this was a face-to-face survey, the random selection of the target person (Kish-Selection) in the household was always carried out with an adult contact person. Therefore, the contents of the study were first discussed with the guardian if the target person was a minor.

In addition to an accompanying official letter of authority for research projects all interested participants was also handed over a written privacy policy, which assured the strict confidentiality of all information given in the questionnaire and informed about the precise handling of personalidentifying data. The participants were assured that their address (identified at an oral onsite survey) was only detected for mapping the data set during the survey phase (and possibly for a subsequent verification of the correct implementation for quality assurance of the data) to ensure the respondents' anonymity in respect of the contracting authority. After completion of the study the relation of these data to the collected contents was irrevocably separated.

\footnotetext{
Author details

${ }^{1}$ Department of Rehabilitation Psychology, University of Applied Sciences Magdeburg-Stendal, Osterburger Str. 25, 39576 Hansestadt Stendal, Germany. ${ }^{2}$ Department of Medical Psychology and Medical Sociology, University of Leipzig, Leipzig, Germany. ${ }^{3}$ Department of Child and Adolescent Psychiatry, University Medical Center Hamburg-Eppendorf, Hamburg, Germany. ${ }^{4}$ Department of Preventive Research, German Sport University Cologne, Cologne, Germany. ${ }^{5}$ University of Mainz, Untere Zahlbacher Str. 8, 55131 Mainz, Germany.
} 
Received: 29 July 2015 Accepted: 20 December 2016 Published online: 26 January 2017

\section{References}

1. Adams RE, Boscarino JA, Galea S. Alcohol use, mental health status and psychological well-being 2 years after the World Trade Center attacks in New York City. Am J Drug Alcohol Abuse. 2006;32:203-24.

2. Andreu Y, Galdon MJ, Dura E, Ferrando M, Murgui S, Garcia A, et al. Psychometric properties of the Brief Symptoms Inventory-18 (Bsi-18) in a Spanish sample of outpatients with psychiatric disorders. Psicothema. 2008; 20:844-50.

3. Asner-Self KK, Schreiber JB, Marotta SA. A cross-cultural analysis of the Brief Symptom Inventory-18. Cultur Divers Ethnic Minor Psychol. 2006;12:367-75.

4. Berman SL, Weems CF, Stickle TR. Existential anxiety in adolescents: prevalence, structure, association with psychological symptoms and identity development. J Youth Adolesc. 2006;35:303-10.

5. Boscarino JA, Adams RE, Figley CR. Mental health service use 1-year after the World Trade Center disaster: implications for mental health care. Gen Hosp Psychiatry. 2004;26:346-58.

6. Boscarino JA, Adams RE, Figley CR, Galea S, Foa EB. Fear of terrorism and preparedness in New York City 2 years after the attacks: implications for disaster planning and research. J Public Health Manag Pract. 2006;12:505-13.

7. Bühner M. Einführung in die Test- und Fragebogenkonstruktion. 2 aktualisierteth ed. München: Pearson Studium; 2006.

8. Carlson LE, Angen M, Cullum J, Goodey E, Koopmans J, Lamont L, et al. High levels of untreated distress and fatigue in cancer patients. Br J Cancer. 2004;90:2297-304.

9. Coley RL, Hernandez DC. Predictors of paternal involvement for resident and nonresident low-income fathers. Dev Psychol. 2006;42:1041-56.

10. Coultas D, Frederick J, Barnett B, Singh G, Wludyka P. A randomized trial of two types of nurse-assisted home care for patients with COPD. Chest. 2005; 128:2017-24.

11. Derogatis L, Fitzpatrick M. The SCL-90-R, the Brief Symptom Inventory (BSI), and the BSI-18. In: Maruish ME, editor. Instruments for adults: The use of psychological testing for treatment planning and outcomes assessment, vol. 3. 3rd ed. 2004. p. 1-41.

12. Derogatis LR. SCL-90-R: Administration, scoring \& procedures manual for the R(evised) version - I. Baltimore: Johns Hopkins University, School of Medicine; 1977

13. Derogatis LR. Brief Symptom Inventory: Administration and procedures manual - I. Baltimore: Clinical Psychometric Research, Inc.; 1982.

14. Derogatis LR. BSI-18: Brief Symptom Inventory 18 - Administration, scoring, and procedures manual. Minneapolis: NCS Pearson; 2000.

15. Derogatis LR, Wise TN. Anxiety and depressive disorders in the medical patient. Washington, D.C.: American Psychiatric Press; 1989.

16. Franke $\mathrm{GH}$. Eine weitere Überprüfung der Symptom-Check-Liste (SCL-90-R) als Forschungsinstrument. Diagnostica. 1992;38:160-7.

17. Franke $\mathrm{GH}$. Erste studien zur güte des brief symptom inventory (BSI). Z Med Psychol. 1997;6:159-66.

18. Franke GH. Effekte der Computeradministration bei der Symptom-Checkliste (SCL-90-R) unter besonderer Berücksichtigung der Itemreihenfolge. Diagnostica. 1999;45:147-53.

19. Franke GH. Brief Symptom Inventory von L. R. Derogatis (Kurzform der SCL90-R) - deutsche Version. Göttingen: Beltz Test; 2000.

20. Franke GH. Möglichkeiten und Grenzen im Einsatz der Symptom-Checkliste SCL-90-R. Verhaltensther Psychosoziale Prax. 2001;33:475-85.

21. Franke GH. Symptom-Checkliste von L.R. Derogatis (SCL-90-R) - deutsche Version. 2, überarbeitete und neunormierteth ed. Göttingen: Beltz Test; 2002.

22. Franke $\mathrm{GH}$. SCL-90®-S. Symptom-Checklist- $90^{\oplus}$-Standard - Manual. Göttingen: Hogrefe; 2014.

23. Franke GH. BSCL. German manual of the Brief Symptom Checklist [German]. Göttingen: Hogrefe; 2016a.

24. Franke GH. Mini-SCL. German manual of the Mini Symptom Checklist [German]. Göttingen: Hogrefe; 2016b.

25. Franke GH, Ankerhold A, Haase M, Jäger S, Tögel C, Ulrich C, et al. Der Einsatz des Brief Symptom Inventory 18 (BSI-18) bei Psychotherapiepatienten. Psychosom Psychother Med Psychol. 2011; 61:82-6.

26. Franke GH, Jäger S, Morfeld M, Salewski C, Reimer J, Rensing A, et al. Eignet sich das BSI-18 zur Erfassung der psychischen Belastung von nierentransplantierten Patienten? Z Med Psychol. 2010;19:30-7.
27. Galdon MJ, Dura E, Andreu Y, Ferrando M, Murgui S, Perez S, et al. Psychometric properties of the Brief Symptom Inventory-18 in a Spanish breast cancer sample. J Psychosom Res. 2008;65:533-9.

28. Geisheim C, Hahlweg K, Fiegenbaum W, Frank M, Schröder B, von Witzleben I. Das Brief Symptom Inventory (BSI) als instrument zur qualitätssicherung in der psychotherapie. Diagnostica. 2002;48:28-36.

29. Gold C, Rolvsjord R, Aaro LE, Aarre T, Tjemsland L, Stige B. Resourceoriented music therapy for psychiatric patients with low therapy motivation: protocol for a randomised controlled trial. BMC Psychiatry. 2005;5:39.

30. Härter M. Ätiologie psychischer Störungen bei chronischen körperlichen Erkrankungen. Rehabilitation. 2002;41(6):357-66.

31. Hu L, Bentler PM. Cutoff criteria for fit indexes in covariance structure analysis. Conventional criteria versus new alternatives. Struct Equation Mod. 1999;6:1-55.

32. Kroenke K, Spitzer RL, Williams JB, Löwe B. An ultra-brief screening scale for anxiety and depression: the PHQ-4. Psychosomatics. 2009;50:613-21.

33. Loewe B, Spitzer MD, Williams JBW, Mussell M, Schellberg D, Kroenke K. Depression, anxiety and somatization in primary care: Syndrome overlap and functional impairment. Gen Hosp Psych. 2008;30:191-9.

34. Löwe B, Wahl I, Rose M, Spitzer C, Glaesmer H, Wingenfeld K, et al. A 4-item measure of depression and anxiety: validation and standardization of the Patient Health Questionnaire-4 (PHQ-4) in the general population. J Affect Disord. 2010;122:86-95.

35. Lüdtke O, Robitzsch A, Trautwein U, Köller O. Umgang mit fehlenden Werten in der psychologischen Forschung. Probleme und Lösungen. Psychol Rundsch. 2007:58:103-17.

36. Meachen SJ, Hanks RA, Millis SR, Rapport LJ. The reliability and validity of the brief symptom inventory-18 in persons with traumatic brain injury. Arch Phys Med Rehabil. 2008;89:958-65.

37. Miguel-Tobal JJ, Cano-Vindel A, Gonzalez-Ordi H, Iruarrizaga I, Rudenstine S, Vlahov D, et al. PTSD and depression after the Madrid March 11 train bombings. J Trauma Stress. 2006;19:69-80.

38. Ming Liu W, Kenji Iwamoto E. Asian American men's gender role conflict: the role of asian values, self-esteem, and psychological distress. Psychol Men Masculinity. 2005;7:153-64.

39. Pakenham Kl. Benefit finding in multiple sclerosis and associations with positive and negative outcomes. Health Psychol. 2005;24:123-32.

40. Petkus AJ, Gum AM, Small B, Malcarne VL, Stein MB, Loebach Wetherell J. Evaluation of the factor structure and psychometric properties of the brief symptom inventory - 18 with homebound older adults. Int J Geriatric Psychiatry; 2009. Published online.

41. Prelow HM, Weaver SR, Swenson RR, Bowman MA. A prelimninary investigation of the validity and reliability of the brief-symptom inventory18 in economically disadvantaged latina american mothers. J Community Psychol. 2005;33:139-55.

42. Recklitis CJ, Parsons SK, Shih MC, Mertens A, Robison LL, Zeltzer L. Factor structure of the brief symptom inventory-18 in adult survivors of childhood cancer: results from the childhood cancer survivor study. Psychol Assess. 2006;18:22-32.

43. Recklitis CJ, Rodriguez P. Screening childhood cancer survivors with the brief symptom inventory-18: classification agreement with the symptom checklist-90-revised. Psychooncology. 2007;16:429-36.

44. Rochlen AB, Mahalik JR. Women's perceptions of male partner's gender role conflict as predictors of psychological well-being and relationship satisfaction. Psychol Men Masculinity. 2004;5:147-57.

45. Roth M, Herzberg PY. Psychodiagnostik in der Praxis: State of the art? Klin Diagn Eval. 2008;1:5-18.

46. Ruggiero KJ, Resnick HS, Acierno R, Coffey SF, Carpenter MJ, Ruscio AM, et al. Internet-based intervention for mental health and substance use problems in disaster-affected populations: a pilot feasibility study. Behav Ther. 2006;37:190-205

47. Schermelleh-Engel K, Moosbrugger. Evaluating the fit of structural equation models: Tests of significance and descriptive goddness-of-fit measures. Methods of Psychological Research. 2003;8(2):23-74.

48. Sherman MD, Sautter F, Lyons JA, Manguno-Mire GM, Han X, Perry D, et al. Mental health needs of cohabiting partners of Vietnam veterans with combat-related PTSD. Psychiatr Serv. 2005;56:1150-2.

49. Spitzer C, Hammer S, Löwe B, Grabe HJ, Barnow S, Rose M, Wingenfeld K, Freyberger HJ, Franke GH. Die Kurzform des Brief Symptom Inventory (BSI- 
18): erste Befunde zu den psychometrischen Kennwerten der deutschen Version. Fortschr Neurol Psychiatrie. 2011;79:517-23.

50. Wang J, Kelly BC, Booth BM, Falck RS, Leukefeld C, Carlson RG. Examining factorial structure and measurement invariance of the Brief Symptom Inventory (BSI)-18 among drug users. Addict Behav. 2010;35:23-9.

51. Zabora J, BrintzenhofeSzoc K, Jacobsen P, Curbow B, Piantadosi S, Hooker C et al. A new psychosocial screening instrument for use with cancer patients. Psychosomatics. 2001;42:241-6.

Submit your next manuscript to BioMed Central and we will help you at every step:

- We accept pre-submission inquiries

- Our selector tool helps you to find the most relevant journal

- We provide round the clock customer support

- Convenient online submission

- Thorough peer review

- Inclusion in PubMed and all major indexing services

- Maximum visibility for your research

Submit your manuscript at www.biomedcentral.com/submit 